\title{
Deprenyl in the management of response fluctuations in patients with Parkinson's disease on levodopa
}

\author{
M SCHACHTER, C D MARSDEN, J D PARKES, P JENNER, AND B TESTA* \\ From the University Department of Neurology, Institute of Psychiatry and King's College Hospital, \\ Denmark Hill, London, and the School of Pharmacy, University of Lausanne, Place du Chateau, \\ Lausanne, Switzerland*
}

SUMMARY Fluctuations in response to levodopa are a common and serious complication of longterm levodopa therapy. It may be possible to prolong the effect of each dose of levodopa by retarding the breakdown of dopamine. The selective monoamine oxidase type B inhibitor deprenyl, which is extensively metabolised to amphetamine and methamphetamine, has this effect as well as possible actions on dopamine release and re-uptake. In a double-blind crossovet trial against placebo, deprenyl prolonged the action of levodopa and produced an objective improvement in mobility in five of 10 patients with dose-related response swings, and a subjective improvement in a further four patients. In another group of seven patients with random fluctuations in symptoms, only two noted subjective improvement, and there was an apparent increase in the severity of response swings in five patients. Deprenyl exacerbated dyskinesias, but had no serious side-effects. We conclude that deprenyl is unlikely to benefit patients with random response swings, and may cause deterioration in such cases. However, it may be a useful adjuvant in the management of dose-related response fluctuations in patients already on optional levodopa therapy.

Dopamine is rapidly catabolised in the brain by monoamine oxidase (MAO) and catechol-Omethyl transferase (COMT). ${ }^{1}$ Despite frequent oral doses of levodopa, symptom fluctuation is common in Parkinsonian patients after two to three years of levodopa treatment, and often becomes increasingly severe and disabling.? 3 Retarding the breakdown of dopamine by the inhibition of either MAO or COMT might prolong the anti-Parkinsonian effect of each separate dose of levodopa and reduce symptom fluctuations. ${ }^{45}$ However, the combination of levodopa with most available MAO inhibitors is liable to cause hypertensive crises, as well as requiring rigid dietary restrictions. ${ }^{6}$ Two types of MAO are now recognised, ${ }^{7}$ and 1-deprenyl (phenylisopropyl-methylpropinylamine hydrochloride) selectively inhibits MAO type $B,{ }^{8}$ which is the predominant type in human brain. ${ }^{9}$ 1-depreny1 $10 \mathrm{mg}$ daily, given without levodopa, has been shown to increase cerebral dopamine levels, with minimal effect on other transmitter

Address for reprint requests: Dr $M$ Schachter, King's College Hospital, Denmark House, London SE5 9RS.

Accepted 16 July 1980 amines. ${ }^{10}$ It does not cause dangerous hypertensive reactions with levodopa or with tyraminecontaining foods. ${ }^{11}$ In addition to its action as a monoamine oxidase inhibitor, 1-deprenyl may also cause the release, and block the re-uptake, of catecholamines in the brain. ${ }^{12} 13$

There have been several clinical studies of the combined use of levodopa and deprenyl in Parkinson's disease. ${ }^{14-21}$ Overall, deprenyl appears to enhance and prolong the anti-Parkinsonian effect of levodopa, while aggravating dopaminergic side-effects in some cases. Deprenyl alleviates symptom fluctuations in some patients with dose-related response swings on levodopa (with or without a decarboxylase inhibitor), although the extent of the benefit varies considerably. ${ }^{14-20}$ We have studied the action of deprenyl in Parkinsonian patients with response swings on levodopa, and have also determined whether deprenyl undergoes significant conversion to amphetamine in these patients, as other studies have suggested. ${ }^{1122}$

\section{Patients and methods}

Nineteen patients with idiopathic Parkinson's disease 
14 male and five female, aged 45 to 70 years (mean $56 \cdot 3$ years), were studied as out-patients. Disease severity ${ }^{22}$ was as follows: stage II, one subject; stage III, 12 subjects; stage IV, three subjects; and stage $\mathrm{V}$, three subjects. Disease duration ranged from three to 16 years (mean $9 \cdot 6$ years). Fifteen patients were taking levodopa 0.4 to 2 g daily with carbidopa (mean daily intake of levodopa $1 \cdot 1 \mathrm{~g}$ ), and four patients were taking levodopa $1 \cdot 5-2 \cdot 5 \mathrm{~g}$ daily without carbidopa (mean $1.84 \mathrm{~g}$ ). The duration of levodopa treatment ranged from two to nine years (mean 6.2 years). All the subjects had moderate to severe symptom fluctuations on treatment. The type of fluctuation ${ }^{2}$ was defined as follows:

(i) Dose related: 11 patients with end-of-dose akinesia, including peak-dose dyskinesia, four with freezing episodes, and two with early-morning akinesia;

(ii) Random: eight patients with rapid and unpredictable oscillations in symptoms ("yo-yo").

Drugs Each patient was given deprenyl and placebo for separate two-week periods, double-blind. Deprenyl $5 \mathrm{mg}$ was given twice daily at 08.00 and 12.00 hours approximately. During the trial, levodopa dosage was increased if Parkinsonian symptoms increased, and reduced if dyskinesia became unacceptable. The dosage of levodopa was monitored from day to day by the patients themselves and was reviewed by the doctor at each assessment. In 11 patients taking amantadine or anticholinergics or both, the dosage of these drugs remained unchanged throughout the trial.

Assessment In the week before commencing the trial, the optimum dosage and timing of levodopa was determined for each patient. There were four further weekly assessments by the same observer. On each visit an overall assessment of mobility and dyskinesia was made. In addition, each patient recorded the following daily throughout the trial:

(1) mobility hourly while awake, on a scale from 0 to 4 :

$0=$ normal mobility

$1=$ full mobility indoors, needs assistance in going out

$2=$ needs some assistance both at home and outside

$3=$ needs considerable assistance but retains some mobility

$4=$ chair or bed-bound

(2) dyskinesia, hourly over the same period, on a scale from 0 to 3 :

$0=$ no dyskinesia

$1=$ mild dyskinesia, brief duration

$2=$ moderate dyskinesia

$3=$ severe, prolonged dyskinesia

(3) the number of freezing episodes each day

(4) the dosage and timing of levodopa

(5) any side-effects.

Full blood count, ESR, serum biochemistry, ECG, pulse and lying and standing blood pressure was noted before the trial, and after each two-week treatment period. In six patients 24-hour urine output was collected whilst they were taking deprenyl (see below).

Assessment of results At the end of the trial both the patient and the observer compared the two treatment periods. The patient was asked which period was preferable in terms of severity of symptom fluctuation and overall mobility, while taking into account any increase in dyskinesia or the emergence of any side-effects. The observer made a similar comparison on the basis of his weekly assessments, and taking note of comments from the patient's family.

For further assessment, mean hourly mobility and dyskinesia scores, the mean daily number of freezing episodes, and the mean daily levodopa dosage were all determined from the patient's own records. The final week of the placebo period and the final week of the deprenyl period are compared in the Results section.

Studies of deprenyl metabolism (P Jenner and $B$ Testa) Urine levels of deprenyl, methylamphetamine and amphetamine were determined by gasliquid chromatography according to a modification of the method of Campbell, ${ }^{24}$ using p-chloramphetamine as internal standard. The enantiomeric composition of the amphetamine and methylamphetamine excreted was determined by the method of Beckett and Testa. ${ }^{25}$

\section{Results}

Seventeen of the nineteen patients completed the trial. One patient developed a chest infection and reverted to standard treatment. Another patient took deprenyl very irregularly, and valid assessment was not possible.

\section{Patients' and doctor's qualitative assessment}

The comparisons of deprenyl with placebo are summarised in table 1. Patients in the end-ofdose akinesia group had a significantly greater preference for deprenyl than patients in the random oscillations group $(\mathrm{p}<0.05$, Fisher's exact test). Using the same statistical test, there was no difference between the two groups with respect to the doctor's preference for deprenyl rather than placebo.

Quantitative comparison of deprenyl and placebo Comparisons of mean hourly mobility and dyskinesia scores in all patients are shown in figures 1 and 2, and figure 3 shows the percentage of waking time when the mobility score reached three or four (ie severe disability). There were considerable variations in individual responses to deprenyl. Overall, there was an improvement in mean hourly mobility scores in the random oscillation group, but not in the end-of-dose 
Table 1 Patients' and doctor's comparison of deprenyl and placebo

\begin{tabular}{|c|c|c|c|c|c|c|}
\hline & \multicolumn{3}{|c|}{ Patients' comparison* } & \multicolumn{3}{|c|}{ Doctor's comparison $\dagger$} \\
\hline & $\begin{array}{l}\text { Deprenyl } \\
\text { better }\end{array}$ & $\begin{array}{l}\text { Placebo } \\
\text { better }\end{array}$ & $\begin{array}{l}\text { No } \\
\text { difference }\end{array}$ & $\begin{array}{l}\text { Deprenyl } \\
\text { better }\end{array}$ & $\begin{array}{l}\text { Placebo } \\
\text { better }\end{array}$ & $\begin{array}{l}\text { No } \\
\text { difference }\end{array}$ \\
\hline $\begin{array}{l}\text { End-of-dose akinesia } \\
\text { (10 patients) }\end{array}$ & 9 & 1 & 0 & 7 & 1 & 2 \\
\hline $\begin{array}{l}\text { Random oscillations } \\
\text { ( } 7 \text { patients) }\end{array}$ & 2 & 0 & 5 & 2 & 0 & 5 \\
\hline
\end{tabular}

* = Deprenyl preference significantly higher in end-of-dose group $(\mathrm{p}<0.05$, Fisher's exact test)

$\dagger=$ No significant difference in deprenyl preference in either end-of-dose or random groups (Fisher's exact test)

(For statistical comparison, "deprenyl better" was compared to the sum of the other two categories.)

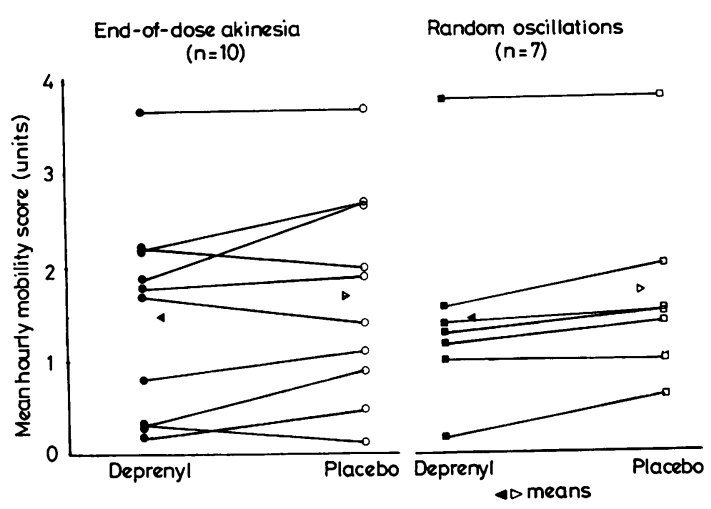

Fig 1 Mean hourly mobility scores for individual patients on deprenyl and placebo. $\varangle \triangleright$ indicate means for group.

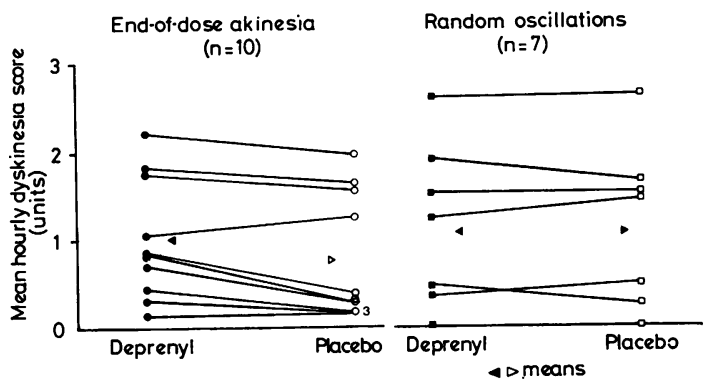

Fig 2 Mean hourly dyskinesia scores for individual patients on deprenyl and placebo. $\triangleleft \triangleright$ indicate means for group.

group, although five patients in the latter group showed improvements in score of 0.3 to 0.8 points. At the same time there was an increase in mean hourly dyskinesia scores in the end-ofdose group, but not in the random group. There was no difference in either group in the daily levodopa dosage on deprenyl and placebo. In view of the changes in mean hourly mobility scores already summarised the results shown in figure 3 are surprising. There was a decrease in the number of periods of severe immobility in the end-of-dose group, but there was an increase in such periods in the random group. Changes in the number of freezing episodes are not shown, since patients found it difficult to record these accurately: in particular, if several such episodes occurred within an hour usually only one was noted.

The data and statistical analysis derived from Figures 1 to 3 are summarised in table 2 .

\section{Duration of action of each dose of levodopa}

Estimates of the duration of action of individual doses of levodopa were made for each of the patients in the end-of-dose group, using the patients' record charts supplemented by the observations of other members of the patients' families. The median duration of levodopa action on placebo was 150 minutes (range 120-210 minutes), The difference was not statistically significant (Wilcoxon's test). However, in the five patients with improvements in mean hourly

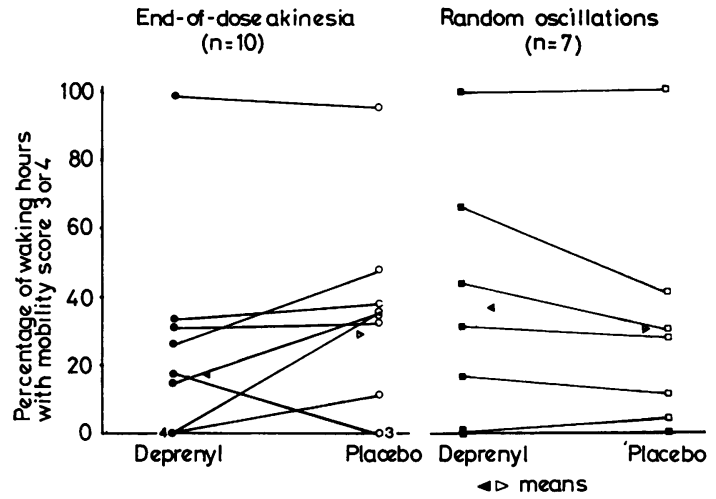

Fig 3 Percentage of waking time with severe disability (mobility score 3 or 4) for individual patients on deprenyl and placebo. $\backslash \triangleright$ indicates mean for group. 
Table 2 Summary of response to deprenyl compared to placebo

\begin{tabular}{|c|c|c|c|c|}
\hline & \multicolumn{2}{|c|}{ End-of-dose group $(n=10)$} & \multicolumn{2}{|c|}{ Random group $(n=7)$} \\
\hline & Deprenyl & Placebo & Deprenyl & Placebo \\
\hline $\begin{array}{l}\text { Hourly mobility score* (units) } \\
\text { Hourly dyskinesia score }{ }^{*} \\
\text { (units) }\end{array}$ & $\begin{array}{l}1 \cdot 5 \pm 0 \cdot 3 \\
1 \cdot 0 \pm 0 \cdot 2\end{array}$ & $\begin{array}{l}1 \cdot 7 \pm 0 \cdot 3 \\
0 \cdot 8 \pm 0 \cdot 2\end{array}$ & $\begin{array}{l}1 \cdot 5 \pm 0.4 \\
1 \cdot 2 \pm 0.3\end{array}$ & $\begin{array}{l}1 \cdot 7 \pm 0 \cdot 3 \\
1 \cdot 2 \pm 0 \cdot 3\end{array}$ \\
\hline $\begin{array}{l}\text { Percentage waking time } \\
\text { with severe disability }\end{array}$ & $22 \cdot 0 \pm 9$ & $29 \pm 8 \cdot 5$ & $36 \cdot 5 \pm 12 \cdot 5$ & $30 \cdot 5 \pm 11 \cdot 5$ \\
\hline
\end{tabular}

Figures are means \pm 1 SEM. High scores indicate decreased mobility or increased dyskynesia.

All statistical comparisons using Wilcoxon's test. Differences between means not significant unless indicated.

* =- Mobility score lower on deprenyl than placebo in random group $(p<0.01)$

$\dagger=$ Dyskinesia score higher on deprenyl than placebo in end-of-dose group $(p<0.025)$

$\ddagger=$ Percentage of day with severe disbility higher on placebo than deprenyl in end-of-dose group $(p<0.02)$ and

higher on deprenyl than placebo in random group $(p<0.05)$

mobility scores of $\mathbf{0 . 3}$ points or more, the difference was statistically significant $(p<0.05$, Wilcoxon's test), although the medians were the same as for the group as a whole.

\section{Metabolism of deprenyl}

In the six patients studied, the 24-hour excretion of amphetamine ranged from 0.45 to $1.63 \mathrm{mg}$ (mean $1.10 \mathrm{mg}$ ) and of methylamphetamine from 1.45 to $4.03 \mathrm{mg}$ (mean $2.47 \mathrm{mg}$ ). Urinary $\mathrm{pH}$ was 5.70 or higher in all cases, and was thus more alkaline than that required for maximal amphetamine excretion. Examination of the enantiomeric composition of the amphetamine and methylamphetamine revealed in each case predominance of the $\mathbf{R}(-)$-isomer. Less than $6.5 \%$ of the $S(+)$-isomer was present in any of the samples, and this was attributed to the enantiomeric impurity of the administered 1-deprenyl. No unchanged deprenyl was detected in the urine of any of the patients. These results are substantially in agreement with those of Reynolds et $a{ }^{22}$

\section{Side-effects and toxicity}

The increase in dyskinesias accompanying deprenyl therapy has been noted above. One patient had slight epigastric discomfort after each dose of deprenyl. No other side-effects attributable to deprenyl were noted during the trial. Pulse rate, blood pressure, blood count, erythrocyte sedimentation rate, serum biochemistry and the electrocardiogram remained unchanged in all patients taking deprenyl.

\section{Discussion}

Half the patients with dose-related response swings in this study showed improvement in mean hourly mobility scores and prolongation of levodopa action, accompanied by increased dyskinesia but little change in levodopa dosage. The majority of patients in this group preferred not to reduce the dose of levodopa, despite the exacerbation of dyskinesia, as they found that such a reduction impaired mobility. Only one of the 10 patients in this group did not express a preference for deprenyl rather than placebo. In contrast, only two of seven patients in the random group preferred deprenyl, and the doctor's assessment was in agreement with this. This occurred despite slight improvements in mean hourly mobility scores in this random group, and only a minor increase in dyskinesia. The reason for this can be inferred from figures 1 and 3. In the end-of-dose group the total duration of periods of severe disability was reduced by deprenyl, while in the random group there was an increase in such periods. Since the overall mean hourly mobility score in the random group generally showed an improvement, it follows that there were more severe swings from "good" to "bad" periods in these patients.

No serious side-effects were encountered during the trial and no systemic toxicity was observed. Other studies ${ }^{14-20}$ have reported much more frequent side-effects, including nausea, postural hypotension, dryness of the mouth, anxiety, insomnia and hallucinations. These trials were all of longer duration than the present one, lasting from one month to two years, and a possible accumulation of deprenyl during prolonged treatment ${ }^{26}$ may be responsible for increased toxicity, although this theory is not supported by more recent work. ${ }^{27}$ Further reduction in levodopa dosage would also be anticipated during a longer trial.

The mechanism of "on-off" effects remains poorly understood. Although variations in plasma dopa and cerebral dopamine levels may be important in patients with dose-related fluctuations, they do not explain apparently random 
swings from akinesia to dyskinesia. Changes in dopamine receptor sensitivity during chronic levodopa therapy have been proposed, but evidence for this in man is limited. ${ }^{28} 29$

The mode of action of deprenyl is complex. As far as the drug's anti-Parkinsonian activity is concerned, it is uncertain whether its role as a selective MAO inhibitor is of greater importance than effects on dopamine release and re-uptake, ${ }^{1213}$ which may be due to metabolites of deprenyl. ${ }^{22}$ Furthermore, there is no doubt that there is substantial conversion of deprenyl to amphetamine and methylamphetamine, as this study confirms. ${ }^{22}$ Indeed, we were unable to detect unchanged deprenyl in the urine of any patient. As expected, the conversion occurs with retention of configuration, the $\mathrm{R}-(-)$-isomers of the amphetamines being excreted predominantly. This isomer of amphetamine has a minor antiParkinsonian effect. ${ }^{30}$ The site of interconversion is probably the liver, but any amphetamine formed there will readily cross the blood-brain barrier.

Despite these uncertainties, deprenyl appears to be a useful adjuvant in the management of dose-related response swings in patients already on optimal levodopa therapy. Subsequent experience suggests that the benefits of a smoother response to levodopa obtained in such patients by adding deprenyl may continue for many months. However, uncontrollable, random oscillations appear in about $50 \%$ of those treated with this combination for six months or more.

Although the drug is not generally available, we believe that deprenyl has a definite role in the treatment of Parkinson's disease at this time. In patients who develop disabling dose-related response swings we would advocate firstly a readjustment of the timing of levodopa dosage, then the addition of deprenyl, which is simple to administer and lacks serious toxicity. If these measures fail, the addition or substitution of a directly-acting dopamine agonist, such as bromocriptine, then might be considered.

We thank Professor J Knoll, of the Semmelweis Medical University, Budapest, for his help and advice, and the Chinoin Pharmaceutical Company, Budapest, for supplies of deprenyl. We also thank Mrs P Asselman for her help in organising the trial.

\section{References}

1 Carlsson, A. Biochemical and pharmacological aspects of Parkinsonism. Acta neurol Scand
1972; 51:11-31.

2 Sweet RD, McDowell FH. The "on-off" response to chronic L-dopa treatment of Parkinsonism. Adv Neurol 1974; 5:331-8.

3 Marsden CD, Parkes JD. "On-off" effects in patients with Parkinson's disease on chronic levodopa therapy. Lancet 1976; I:292-6.

4 Birkmayer W, Hornykiewicz O. Der L-3, 4dioxyphenylalanin (=Dopa) effekt beim Parkinson-syndrome des Menschen. Arch Psychiatr Nervenkrank 1962; 203:560-73.

5 Ericsson AD. Potentiation of the L-dopa effect in man by the use of catechol-O-methyl transferase inhibitors. J Neurol Sci 1971; 14:421-6.

6 Hunter KR, Boakes AJ, Laurence DR, Stern GM. Monoamine oxidase inhibitors and L-dopa. Br Med J 1970; III:388.

7 Johnston JP. Some observations upon a new inhibitor of monoamine oxidase in brain tissue. Biochem Pharmacol 1968; 17:1285-97.

8 Knoll AJ. Analysis of the pharmacological effect of selective monoamine oxidase inhibitors. In: Wolstenholme GEW, Knight TJ, eds. Monoamine oxidase and its inhibition. Amsterdam: Elsevier, 1976; 135-62.

9 Glover V, Sandler M, Owen F, Riley GJ. Dopamine is a monoamine oxidase $B$ substrate in man. Nature 1977; 265:80-1.

10 Riederer P, Youdim MBH, Birkmayer W, Jellinger $\mathrm{K}$. Monoamine oxidase activity during (-)-deprenil therapy: human post-mortem studies. In: Roberts PJ et al ed. Advances in Biochemical Psychopharmacology, vol 19. New York: Raven Press, 1978; 377-82.

11 Sandler M, Glover V, Ashford A, Stern GM. Absence of "cheese effect" during deprenyl therapy: some recent studies. J Neural Transm 1978; 43:209-15.

12 Knoll AJ. The possible mechanism of action of $(-)$-deprenyl in Parkinson's disease. $J$ Neural Transm 1978; 43:177-98.

13 Simpson LL. Evidence that deprenyl, a type B monoamine oxidase inhibitor, is an indirectly acting sympathomimetic amine. Biochem Pharmacol 1978; 27:1591-5.

14 Birkmayer W, Riederer P, Youdim MBH, Linauer W. The potentiation of the anti-akinetic effect after L-DOPA treatment by an inhibitor of MAO-B, deprenyl. J Neural Transm 1975; 36:303-26.

15 Birkmayer W, Riederer P, Ambrozi L, Youdim MBH. Implications of combined treatment with Madopar and L-deprenyl in Parkinson's disease. Lancet 1977; II:439-43.

16 Birkmayer W. Long-term treatment with Ldeprenyl. J Neural Transm 1978; 43:239-44.

17 Lees AJ, Shaw KM, Kohout LJ, Stern GM, Elsworth JD, Sandler M, Youdim MBH. Deprenyl in Parkinson's disease. Lancet 1977; II:791-6.

18 Yahr MD. Overview of present-day treatment of Parkinson's disease. J Neural Transm 1978; 43: 
227-38.

19 Rinne UK, Siirtola T, Sonninen V. L-deprenyl treatment of on-off phenomena in Parkinson's disease. J Neural Trans 1978; 43:253-62.

20 Csanda E, Antal J, Antony M, Csanaky A. Experiences with L-deprenyl in Parkinsonism. J Neural Transm 1978; 43:263-9.

21 Eisler T, Teravainen HT, Lake CR, Murphy D, Kopin IJ. Calne DB. Clinical and biochemical effects of deprenyl in patients with Parkinson's disease. Neurology (Minneap) 1979; 29:553-4.

22 Reynolds GP, Elsworth JD, Blau K, Sandler M, Lees AJ, Stern GM. Deprenyl is metabolised to methamphetamine and amphetamine in man. Br J Clin Pharmacol 1978; 6:542-4.

23 Hoehn MM, Yahr MD. Parkinsonism: onset, progression and mortality. Neurology (Minneap.) $1967 ; 17: 427-42$.

24 Campbell DB. Gas chromatographic measurement of levels of fenfluramine and norfenfluramine in human plasma, red cells and urine, following therapeutic doses. J Chromotogr 1970; 49:442-7.
25 Beckett AH, Testa B. Stereochemical separation and configuration assignation by gas-liquid chromatography. J Chromatogr 1972; 69:285-9.

26 Riederer P, Youdim MBH, Rausch WD, Birkmayer $\mathrm{W}$, Jellinger $\mathrm{K}$, Seemann $\mathrm{D}$. On the mode of action of 1-deprenyl in the human central nervous system. J Neural Transm 1978; 43: 217-26.

27 Riederer P, Reynolds GP. Deprenyl is a selective inhibitor of brain MAO-B in the long-term treatment of Parkinson's disease. Br J Clin Pharmacol 1980; 9:98-9.

28 Lee T, Seemann P, Rajput A. Receptor basis for dopaminergic supersensitivity in Parkinson's disease. Nature 1978; 273:59-61.

29 Direnfeld L, Spero L, Marotta J, Seemann P. The 1-dopa on-off effect: treatment by drug withdrawal and dopamine receptor resensitisation. Ann Neurol 1978; 4:573-5.

30 Parkes JD, Tarsy D, Marsden CD et al. Amphetamines in the treatment of Parkinson's disease. J Neurolog Neurosurg Psychiatry 1975; 38:232-7. 